\title{
Sea Surface Salinity Change since 1950: Internal Variability versus Anthropogenic Forcing
}

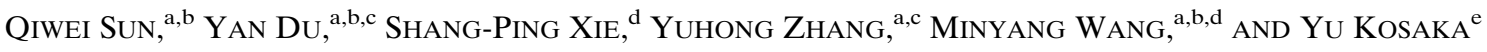 \\ ${ }^{a}$ State Key Laboratory of Tropical Oceanography, South China Sea Institute of Oceanology, Chinese Academy of Sciences, \\ Guangzhou, China \\ ${ }^{\mathrm{b}}$ College of Earth and Planetary Sciences, University of Chinese Academy of Sciences, Beijing, China \\ ${ }^{\mathrm{c}}$ Southern Marine Science and Engineering Guangdong Laboratory, Guangzhou, China \\ ${ }^{\mathrm{d}}$ Scripps Institution of Oceanography, University of California San Diego, La Jolla, California \\ ${ }^{\mathrm{e}}$ Research Center for Advanced Science and Technology, The University of Tokyo, Tokyo, Japan
}

(Manuscript received 11 May 2020, in final form 3 October 2020)

\begin{abstract}
Using an eastern tropical Pacific pacemaker experiment called the Pacific Ocean-Global Atmosphere (POGA) run, this study investigated the internal variability in sea surface salinity (SSS) and its impacts on the assessment of long-term trends. By constraining the eastern tropical Pacific sea surface temperature variability with observations, the POGA experiment successfully simulated the observed variability of SSS. The long-term trend in POGA SSS shows a general pattern of salty regions becoming saltier (e.g., the northern Atlantic) and fresh regions becoming fresher, which agrees with previous studies. The 1950-2012 long-term trend in SSS is modulated by the internal variability associated with the interdecadal Pacific oscillation (IPO). Due to this variability, there are some regional discrepancies in the SSS 1950-2012 long-term change between POGA and the free-running simulation forced with historical radiative forcing, especially for the western tropical Pacific and southeastern Indian Ocean. Our analysis shows that the tropical Pacific cooling and intensified Walker circulation caused the SSS to increase in the western tropical Pacific and decrease in the southeastern Indian Ocean during the 20-yr period of 1993-2012. This decadal variability has led to large uncertainties in the estimation of radiativeforced trends on a regional scale. For the 63-yr period of 1950-2012, the IPO caused an offset of $\sim 40 \%$ in the radiativeforced SSS trend in the western tropical Pacific and $\sim 170 \%$ enhancement in the trend in the southeastern Indian Ocean. Understanding and quantifying the contribution of internal variability to SSS trends helps improve the skill for estimates and prediction of salinity/water cycle changes.
\end{abstract}

KEYWORDS: Tropics; Atmosphere-ocean interaction; Climate change; Salinity; Decadal variability; Trends

\section{Introduction}

The global mean surface temperature (GMST) has been increasing since the industrial revolution owing to the increase in greenhouse gas concentrations, with profound impacts on climate such as sea level rise and increasing occurrences of extreme climate events (Church and White 2006; Church et al. 2004; Diffenbaugh et al. 2005; Wu et al. 2011). The response of rainfall or the hydrological cycle to global warming has been widely investigated (Chadwick et al. 2013, 2014; Held and Soden 2006; Huang et al. 2013; Ma et al. 2018; Seager et al. 2010; Xie et al. 2010). The precipitation minus evaporation $(P-E)$ change over the ocean follows a "wet-gets-wetter" pattern in response to spatially uniform sea surface temperature (SST) warming (Chou et al. 2009; Held and Soden 2006). In reality, SST warming varies in space; moreover, its "warmer-gets-wetter" patterns affect tropical precipitation change (Xie et al. 2010). The coverage of historical rainfall observations is too sparse to test these hypotheses. As an "ocean rain gauge" the climatological mean sea surface

Supplemental information related to this paper is available at the Journals Online website: https://doi.org/10.1175/JCLI-D-200331.s1.

Corresponding author: Yan Du, duyan@scsio.ac.cn salinity (SSS) is highly correlated with the surface $P-E$ flux field, reflecting the balance between ocean advection and mixing processes and $P-E$ forcing at the ocean surface (Durack et al. 2012; Schmitt 2008; Yu 2011). SSS provides an opportunity to assess and understand the hydrological cycle changes on global and regional scales (Boyer et al. 2005; Curry et al. 2003; Durack and Wijffels 2010; Gordon and Giulivi 2008; Helm et al. 2010; Hosoda et al. 2009; Skliris et al. 2014; Terray et al. 2012; Yu 2011; Yu et al. 2020). On a global scale, over the last 50 years, SSS changes reflect an intensification of the mean climatological SSS patterns. Salty regions are becoming saltier and vice versa for current fresh regions such as the western Pacific (Durack and Wijffels 2010; Durack et al. 2012; Durack 2015). On a regional scale, ocean dynamic processes, including ocean advection and mixing, play an important role in SSS changes such as in the subduction zone of the northern Atlantic and western boundary current regions of the North Pacific (Du et al. 2019; Liu et al. 2019; Ponte and Vinogradova 2016; Vinogradova and Ponte 2013, 2017; Yu 2011).

Despite a steady increase in atmospheric greenhouse gases, surface and atmospheric global warming has slowed down since the late 1990s largely owing to modulation by internal variability, specifically the interdecadal Pacific oscillation (IPO) (Fyfe et al. 2016; Kosaka and Xie 2013; Medhaug et al. 2017; Xie and Kosaka 2017). The negative phase of the IPO contributed to this recent "hiatus" (England et al. 2014; Kosaka and Xie 2016; Meehl et al. 2016, 2013). With SST 
cooling in the equatorial central and eastern Pacific, the enhanced trade winds push the warm water westward, exhibiting an east-west contrast change. The see-saw structure not only modulates temperature but also regulates precipitation changes in the tropical Pacific (Dai and Bloecker 2019; Dong and Dai 2015). Few studies have investigated whether internal variability also modulates salinity changes. In fact, SSS has increased in the western tropical Pacific because of the windinduced Walker circulation strengthening during the past 20 years since the early 1990s (Du et al. 2015), in contrast to the freshening trend over the 50-yr period of 1950-2000 (Durack and Wijffels 2010). Decadal variability can either accelerate or slow down regional temperature and salinity changes, complicating the long-term trend estimates from observations that are often limited in length and coverage. Owing to changes in observational coverage, there are inherent step changes between the historical hydrographic database coverage and Argo from 2003. This leads to step changes in observations that provide little insight into how atmospheric and coupled modes of variability affect ocean properties. This raises important questions: How does internal variability affect the long-term trend in salinity and how is the internal variability of salinity related to that of SST?

This study uses an atmosphere-ocean coupled model that includes both radiative forcing and observed variability of the eastern tropical Pacific SST to study the SSS changes (see section 2). Despite biases in the models, the results from the Pacific Ocean-Global Atmosphere (POGA) experiment are in good agreement with the observations and can suitably reproduce radiative-forced and internal variability in SSS. On the decadal scale, owing to the climate decadal variability such as the IPO, the internal variability in SSS has been large enough to affect regional trends since the mid-twentieth century.

The remainder of this paper is organized as follows. Section 2 briefly presents the data and experimental methods. Section 3 describes the results from the POGA simulation with regard to the internal variability and long-term trends in response to global warming, whereas section 4 discusses the relationship of the components of the SSS change. Section 5 focuses on the physical mechanisms for internal variability of SSS, and section 6 compares two epochs to further understand the contribution of the internal variability to trend estimates. Finally, section 7 presents the conclusions with discussion.

\section{Data and methods}

\section{a. Observations and reanalysis datasets}

The monthly mean of three SSS datasets were used, as follows: 1) EN4 version 4.2.1, quality-controlled subsurface ocean temperature and salinity profiles and objective analyses provided by the Met Office Hadley Centre (Good et al. 2013); 2) monthly objectively analyzed subsurface temperature and salinity of datasets from Ishii et al. (2006), herein called ISHII, archived at the National Center for Atmospheric Research (NCAR), Computational and Information Systems Laboratory; and 3) Ocean Reanalysis/Analysis System 4 datasets (ORAS4), taken from the European Centre for Medium-Range Weather Forecasts (ECMWF) (Balmaseda et al. 2013). Note that all datasets are impacted by the pre- to post-Argo step change in data availability, which affects the accuracy of trend estimates from these products. Durack and Wijffels (2010) have compared previous studies and estimated the 50-yr linear trends of salinity using an enhanced methodology to reduce errors from the spatial coverage of historical data, the seasonal cycle, and the El NiñoSouthern Oscillation (ENSO) signal. In this paper, for simplicity, we compare the EN4, ISHII, and ORAS4 datasets (Fig. S1 in the online supplemental material) to reduce the data biases and ensure the consistency of the conclusions as much as possible.

The SST data were obtained from the monthly Optimum Interpolation Sea Surface Temperature (OISST) version 2, provided by the National Oceanic and Atmospheric Administration (NOAA) (Reynolds et al. 2002). The IPO index is defined as the difference between the SST anomalies averaged over the central equatorial Pacific $\left(10^{\circ} \mathrm{S}-10^{\circ} \mathrm{N}, 170^{\circ} \mathrm{E}-90^{\circ} \mathrm{W}\right)$, and the average of the SST anomaly (SSTA) in the northwestern $\left(25^{\circ}-45^{\circ} \mathrm{N}, 140^{\circ} \mathrm{E}-\right.$ $\left.145^{\circ} \mathrm{W}\right)$ and southwestern Pacific $\left(50^{\circ}-15^{\circ} \mathrm{S}, 150^{\circ} \mathrm{E}-160^{\circ} \mathrm{W}\right)$ (Henley et al. 2015). Observed surface winds and sea level pressure (SLP) are available from the ECMWF interim reanalysis (ERA-Interim; Dee et al. 2011). Further, precipitation and evaporation datasets were used to calculate the surface freshwater flux, provided by the Global Precipitation Climatology Project (GPCP) (Adler et al. 2003) and the Objectively Analyzed Air-Sea Heat Fluxes (OAFlux) (Yu and Weller 2007), respectively. In addition, precipitation and evaporation data from ERA-Interim were used for comparison with the GPCP precipitation and OAFlux evaporation to further verify our results (Fig. S2). The observed surface currents were obtained from the Ocean Surface Currents Analyses Real Time (OSCAR) (Bonjean and Lagerloef 2002). The monthly mean sea surface height (SSH) was taken from the Archiving, Validation, and Interpretation of Satellite Oceanographic (AVISO) merged products.

\section{b. Model experiments}

Using version 2.1 of the Geophysical Fluid Dynamics Laboratory Coupled Model (CM2.1; Delworth et al. 2006), 10member historical (HIST) and 10-member Pacific Ocean-Global Atmosphere (POGA) experiments were designed. HIST was forced by historical radiative forcing from the Coupled Model Intercomparison Project phase 5 (CMIP5; Taylor et al. 2012) for the period 1861-2005 and representative concentration pathway (RCP) 4.5 afterward. The forcing included greenhouse gases, aerosols, ozone, solar activity cycle (repeating the cycle for the 1996-2008 period after 2009), and land use. In HIST, the internal climate variability evolved freely, and averaging across a 10member ensemble enables isolating the forced response.

In the POGA experiments, the eastern tropical Pacific SST anomalies were restored by Newtonian cooling to follow the Extended Reconstructed SST (ERSST) version 3b observations. The restoring time scale was 10 days for a $50-\mathrm{m}$-deep mixed layer. Here, we restored the eastern tropical Pacific SST anomalies by overriding sensible heat flux to the ocean, as described by Kosaka and Xie (2013). The restoring regions were $15^{\circ} \mathrm{S}-15^{\circ} \mathrm{N}$ and the date line to the American coast, with $5^{\circ}$ buffer zones to the west, north, and south, where the restoring linearly decreased to zero. Outside the eastern tropical 
Pacific, the atmosphere and ocean were fully coupled and free to evolve. Other conditions were the same as those in HIST [see further details in Kosaka and Xie (2013)]. For simplicity, we used the ensemble mean of the 10 simulations, unless noted otherwise. In this study, the prescribed tropical Pacific SST anomalies (denoted as $P_{\text {SST }}$ ) over decadal intervals included internal variability $\left(P_{\mathrm{SST}-\mathrm{I}}\right)$ and radiatively forced change $\left(P_{\text {SST-F }}\right)$. The differences between POGA and HIST represent the effects of the eastern tropical Pacific internal variability.

We evaluated the long-term effect of $P_{\text {SST-F }}$ by testing the significance of the tropical SST difference averaged over the SST restoring region between the HIST ensemble mean and ERSST version 3b. We applied the Mann-Kendall test to all combinations with start year from 1896 to 1905 and the end year from 1996 to 2005 to avoid strong edge effects. No combination yielded a trend in SST difference significant at $p<0.1$, indicating that $P_{\mathrm{SST}}$ difference of observations (and hence POGA) from HIST is dominated by internal variability (Kosaka and Xie 2016). In addition, we compared the climatological means in SST, $P-E$, and SSS between the POGA and observations presented in Figs. S1 and S3. The correlations were $0.99,0.84$, and 0.88 , respectively. These results demonstrate the reliability of the model configuration for estimating the internal variability and long-term trend of salinity.

Four statistical methods were used to analyze the results, using the following: 1) empirical orthogonal functions (EOFs) to analyze the primary spatial pattern and temporal variability; 2) 50- and 20-yr linear trends, both using the least squares method; 3) the 7-yr running mean to examine decadal modulations; and 4) subtracting the climatological annual cycles from the monthly time series to eliminate seasonal signals for all data used in the study.

\section{General features of SSS variability}

First, we compare the monthly EOFs of SSS between the POGA and HIST simulation results (Fig. 1). The results distinguish the interannual and decadal variability of SSS from the multidecadal long-term trend under global warming, consistent with the observations (Fig. 1 and Fig. S4). In POGA, the first principal component (PC1) shows remarkable interannual and decadal variability in that its correlations with Niño-3.4 SST and the 7-yr running-mean IPO index are $r=0.83$ and 0.85, respectively, with SSS lagging by 4 months (Fig. 1c and Fig. S6a). The spatial pattern of the first EOF mode in POGA shows that the interannual and decadal SSS changes are related to eastern Pacific SST changes (Fig. 1a and Fig. S5). In recent decades, since the mid-1990s, the SSS has increased in the western tropical Pacific, ITCZ, and SPCZ regions, while it has decreased in the Maritime Continent and southeastern Indian Ocean, which is consistent with previous studies (Du et al. 2015; Hasegawa et al. 2013). The spatial patterns of the SSS are related to the rainfall changes. Walker circulation strengthening and westward shift, due to SST cooling in the eastern tropical Pacific in recent decades, play an important role in these rainfall changes (Dong and Lu 2013; England et al. 2014;
L'Heureux et al. 2013; Ma and Zhou 2016). Although the spatial pattern of HIST is similar to that of the POGA experiment, the HIST PC1 fails to capture the observed evolution of internal variability in that it is significantly different from both the observation-based Niño-3.4 SST and the IPO index but remains correlated with the model internal variability (Fig. 1c and Fig. S6a). Unlike the PC1 of POGA, the single member of the HIST features high-frequency variability (Fig. S7), indicating that its first EOF mode is caused by the internal variability of the model. In addition, a slight discrepancy for a 7-yr running mean of PC1 of HIST between Fig. 1c and Fig. S7d is that the former has a weak rising trend since the 1900s, revealing that different data processing methods and model biases are responsible for the disagreement.

In both HIST and POGA, the second principal component time series (PC2) showed a clear rising trend, especially after the 1960s (Fig. 1f), which is highly correlated with the observed GMST ( $r=0.87$ for POGA, $r=0.91$ for HIST; Fig. S6b), revealing the SSS changes in response to global warming. The long-term SSS trend exhibits a unique spatial pattern on global and regional scales (Figs. 1d,e). In the Atlantic, SSS increases in the subtropics in both hemispheres and decreases in the subpolar northern Atlantic. The former is mainly due to reduced precipitation and salinity transport via oceanic meridional circulation ( $\mathrm{Hu}$ and Fedorov 2019). The latter may be caused by the melting of sea ice, while land ice melt is not simulated in the model (Dukhovskoy et al. 2016; Khan et al. 2014; Lehner et al. 2012; Nummelin et al. 2016). In the subtropical Pacific, a poleward expansion of the Hadley cell, related to moisture effects and atmospheric stratification changes, causes midlatitude warming and rainfall reduction (Fu et al. 2006; Seidel et al. 2008). This leads to an increased frequency of drought events, and thus the SSS increases. In addition, more moisture is transported away by the trade winds from the dry subtropical regions toward the wet tropical regions owing to warmer conditions (Held and Soden 2006). This also leads to an increase in SSS in the subtropical regions.

In the tropical Indo-Pacific, SSS decreases in the western tropical Pacific and southeastern Indian Ocean and increases in the eastern Pacific and the western Indian Ocean. These changes may be related to the rainfall changes associated with the moisture increase (thermodynamic processes), and Walker circulation weakening and/or shifting (dynamical processes) under global warming (Chadwick et al. 2013; Chen et al. 2019; Emori and Brown 2005; Ma and Xie 2013; Ma et al. 2018; Norris et al. 2019). With global warming, increasing moisture results in enhanced precipitation in the rising branch of the Walker circulation (Held and Soden 2006). However, the weakening of the Walker circulation leads to a decrease in rainfall, partially offsetting the moisture effect (Ma et al. 2018; Tokinaga et al. 2012). In addition to the global mean warming effects, the dynamical mechanisms associated with SST patterns are important for regional rainfall redistribution (Xie et al. 2010). Specifically, patterns of shifts in convective regions lead to significantly increased (decreased) precipitation (SSS) in the western Pacific (Fig. 1d and Fig. S4e). Overall, the SSS change implies that the rainfall changes owing to the thermodynamic and dynamical processes. 
(a) POGA SSS EOF-1st $27 \%$

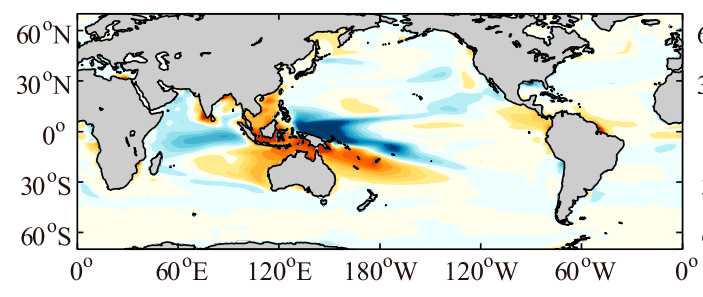

(b) HIST SSS EOF-1st $18 \%$

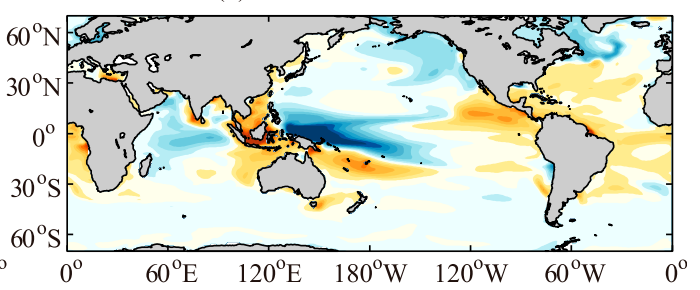

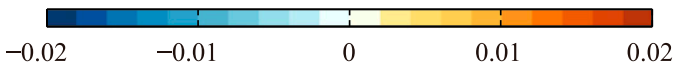

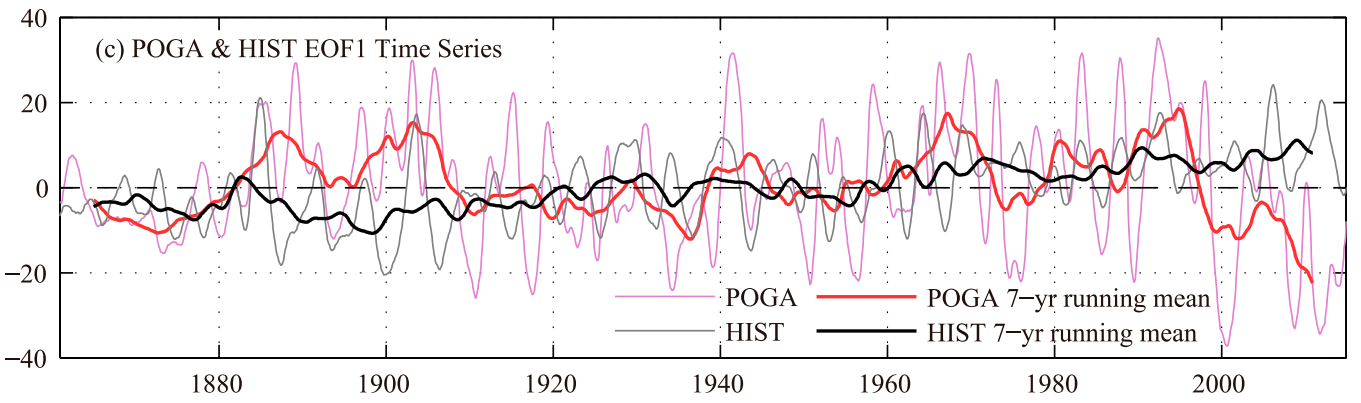

(d) POGA SSS EOF-2nd $12 \%$

(e) HIST SSS EOF-2nd 14\%
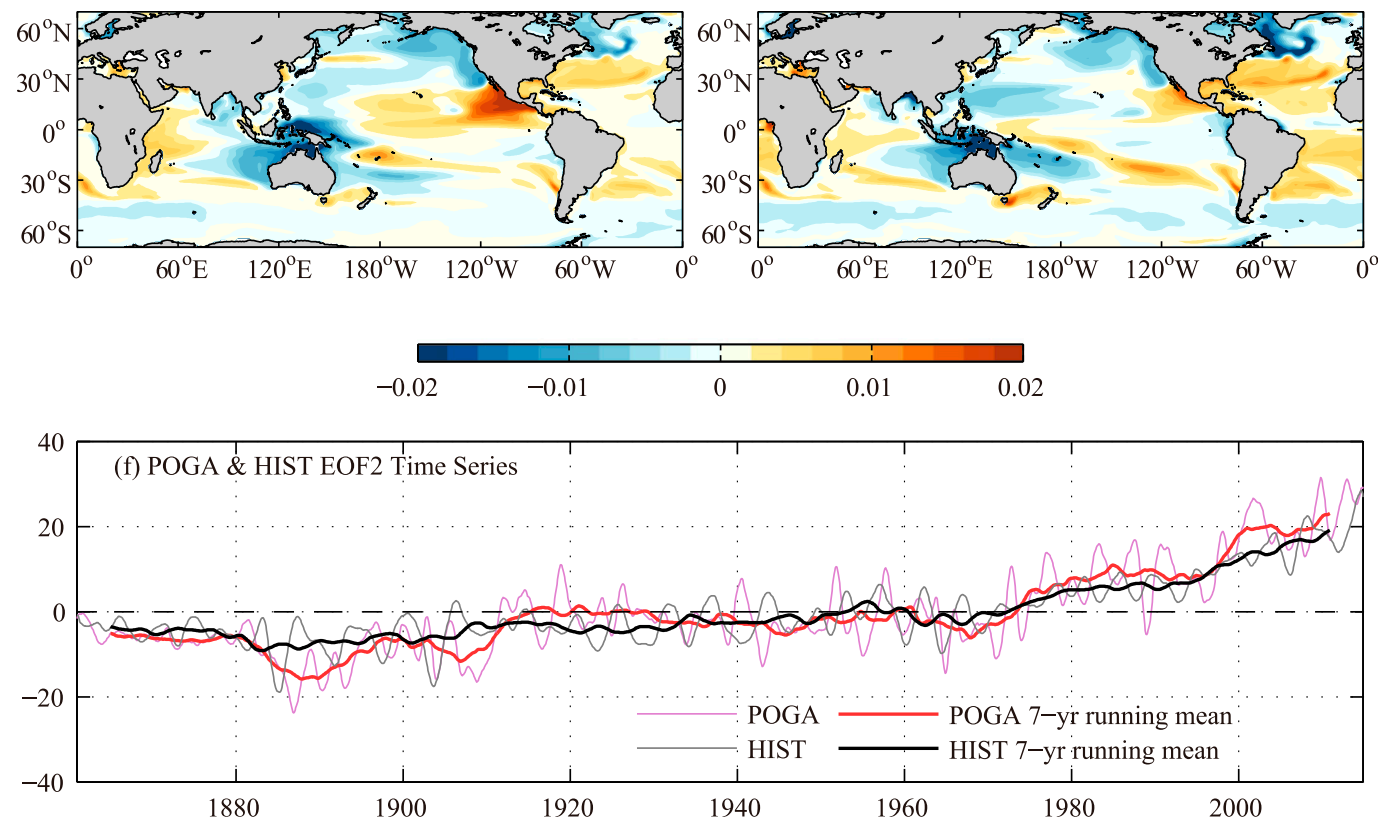

FIG. 1. First EOF mode of unfiltered monthly SSS in (a) POGA and (b) HIST. (c) Corresponding principal component time series (in PSS) in POGA (purple line, with red line for the 7-yr running mean) and HIST (gray line, with black line for the 7-yr running mean). (d)-(f) As in (a)-(c), but for the second EOF mode.

\section{Long-term trend versus internal variability}

The SSS long-term trend estimates among POGA, HIST, and observations during 1950-2008 are mapped in Fig. 2 to validate the POGA results. Both POGA and HIST reproduce the long-term trend features, in agreement with observations on global and very large scales. Over the past 60 years, SSS has increased in the tropical and subtropical Atlantic, subtropical
Pacific, and western Indian Ocean, whereas it has decreased in the western tropical Pacific, southeastern Indian Ocean, and subpolar regions. Overall, rainfall-dominated fresh regions are becoming fresher, while evaporation-dominated salty regions are undergoing saltier, which is consistent with the observational and model studies, following the "wet-gets-wetter" mechanism (Chou and Neelin 2004; Chou et al. 2009; Durack et al. 2012; Held and Soden 2006). However, the spatial 
(a) POGA SSS 1950-2008 Trend

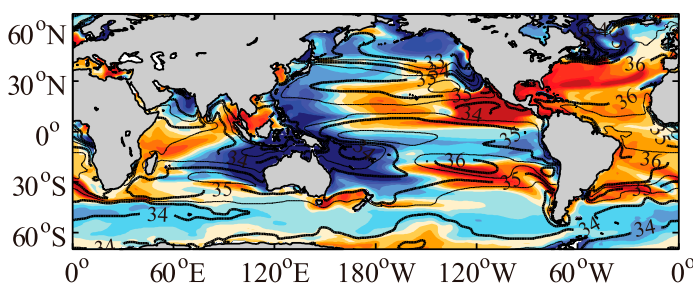

(c) HIST SSS 1950-2008 Trend

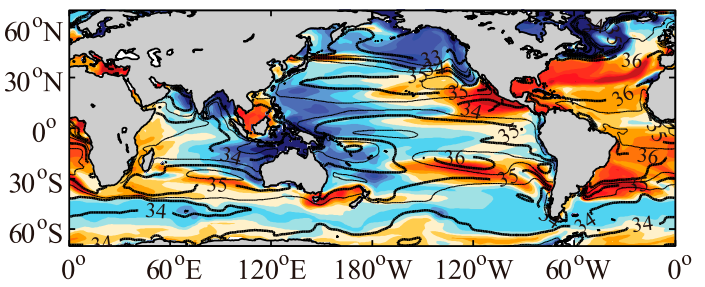

(e) Ishii SSS 1950-2008 Trend

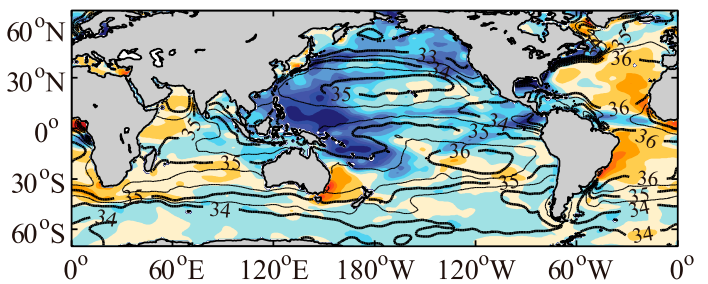

(b) DW10 SSS 1950-2008 Trend

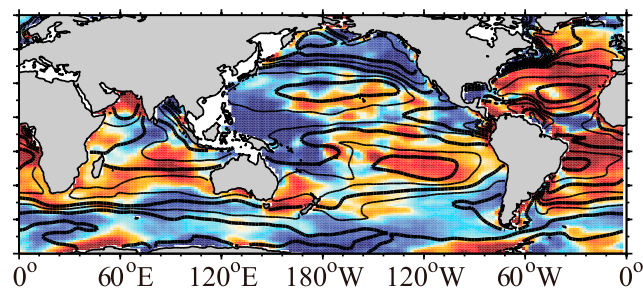

(d) EN4 SSS 1950-2008 Trend

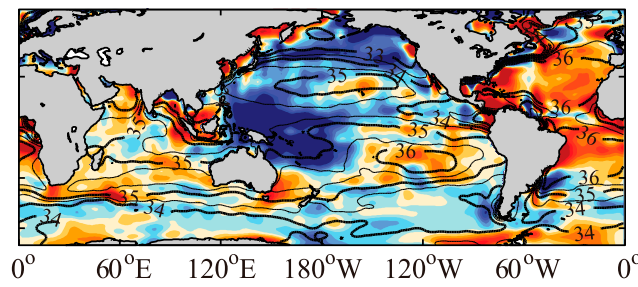

(f) ORAS4 SSS 1960-2008 Trend
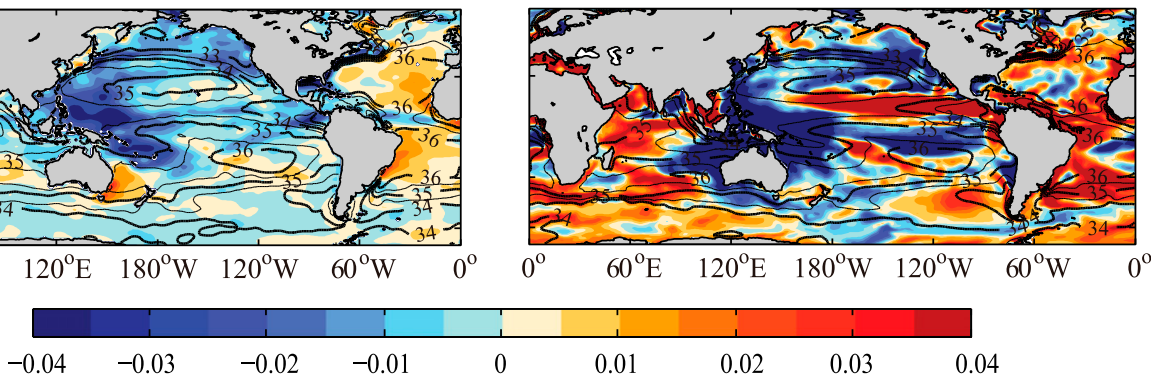

FIG. 2. Six long-term estimates of SSS trend (shading; blue denotes fresher, and red denotes saltier): (a) POGA (analysis period: 1950-2008), (b) Durack and Wijffels (2010; analysis period: 1950-2008), (c) HIST (analysis period: 1950-2008), (d) EN4 (analysis period: 1950-2008), (e) ISHII (analysis period: 1950-2008), and (f) ORAS4 (analysis period: 1960-2008), all scaled to represent equivalent magnitude changes over a 10-yr period (PSS/10 years). In each panel, the corresponding mean SSS from each representative data source is contoured in black (interval of 0.5 PSS).

correlation between the pattern of climatological $P-E$ and long-term $P-E$ changes is weak (Chadwick et al. 2013) probably because of the dynamical processes associated with the atmospheric circulation weakening and/or shifts.

On a regional scale, the discrepancy of the SSS long-term trend is noticeable among POGA, HIST, and the observations, especially in the western tropical Pacific and southeastern Indian Ocean. Compared with the observed SSS changes, the main differences in POGA are that the SSS changes occurred in the southwestern tropical Pacific and southeastern Indian Ocean rather than on both sides of the equator in the western tropical Pacific. Despite similar spatial patterns between POGA and HIST in the western tropical Pacific and southeastern Indian Ocean, the intensity of POGA SSS changes was stronger than that of HIST. It is not immediately clear why the intensity is different between POGA and HIST estimates, despite their EOF2s having the same magnitude. Considering the limits of sparse and discontinuous observational datasets, biases from numerical simulation, and uncertainties from internal variability, it was difficult to accurately estimate the radiatively forced long-term SSS trend.
To investigate the discrepancies in the estimated regional SSS trend, POGA and HIST SSS changes were compared with observational datasets in the northern Atlantic, western tropical Pacific, and southeastern Indian Ocean (Fig. 3 and Fig. S8). In the northern Atlantic, POGA, HIST, and EN4 SSS have all continued to increase since the 1960s, which is consistent with the results from the POGA PC2 (Figs. 3c,f). There are, however, discrepancies in the western tropical Pacific and southeastern Indian Ocean among POGA and HIST (Figs. 3d,e). Although the SSS of HIST has shown a weak decreasing trend since the 1960s in the western tropical Pacific and southeastern Indian Ocean, significant decadal variability, especially in the past three decades, appears in the POGA and observed datasets (Figs. 3a,b), largely affecting the long-term trend estimates. In detail, POGA SSS has continuously decreased since the 1970s and abruptly increased since around 1993; it became slightly fresher during 2000-04, and has again increased since 2005 in the western tropical Pacific, nearly opposite to the SSS changes in the southeastern Indian Ocean. This decadal variability coincides with the POGA's first mode, a pattern with a reverse change between the western tropical Pacific and 
(a) WP EN4 and POGA SSS

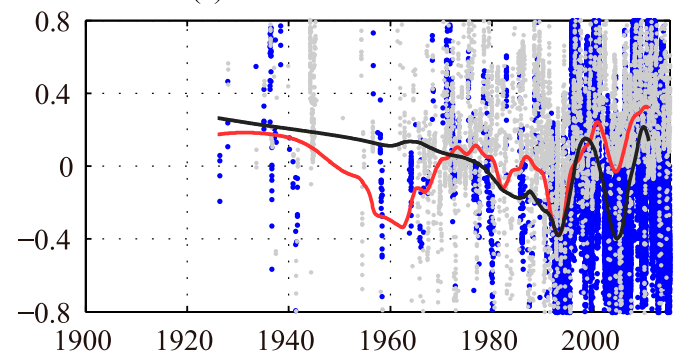

(b) SEIO EN4 and POGA SSS

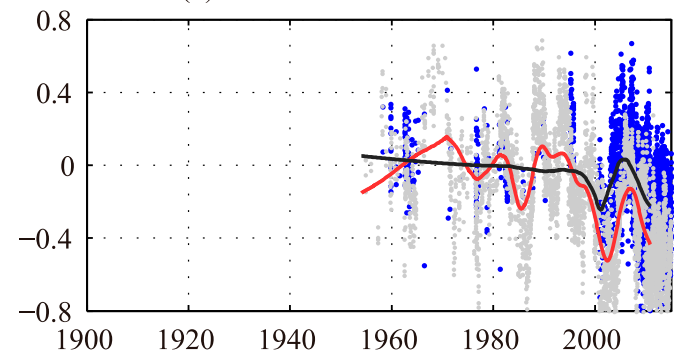

(c) NAO EN4 and POGA SSS

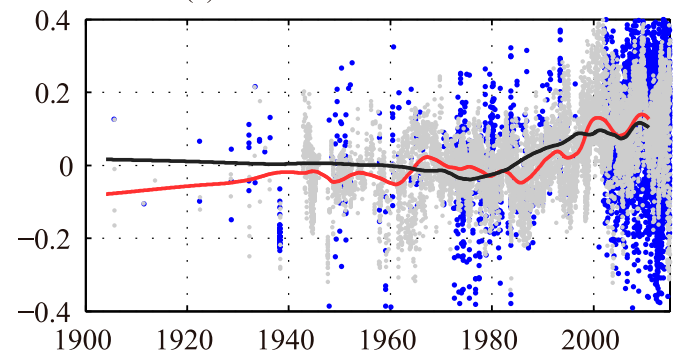

(d) WP HIST and POGA SSS

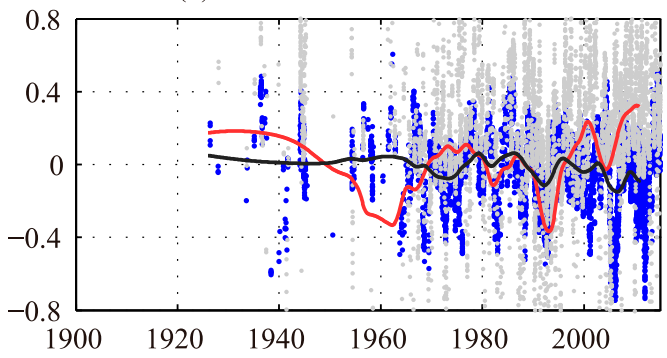

(e) SEIO HIST and POGA SSS

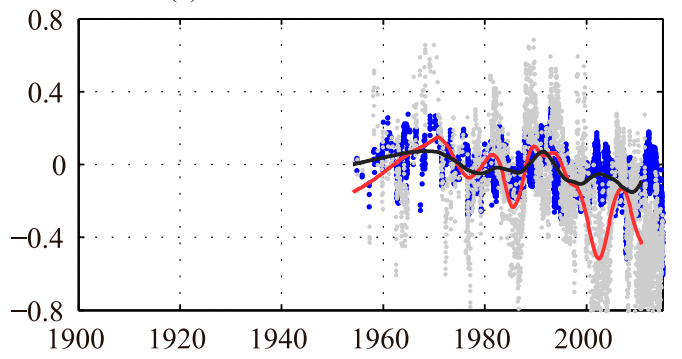

(f) NAO HIST and POGA SSS

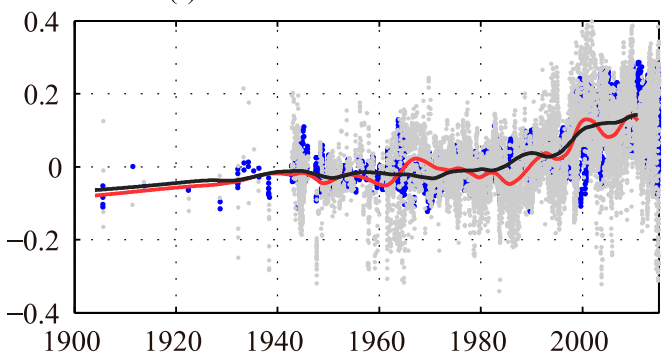

(g) Location of WP, SEIO and NAO

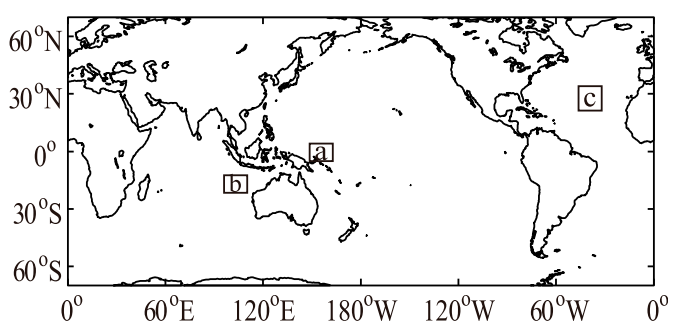

FIG. 3. SSS anomalies (in PSS) in the EN4 profiles (blue dots) and POGA data (gray dots) in (a) the western tropical Pacific $\left(2^{\circ} \mathrm{S}-2^{\circ} \mathrm{N}, 150^{\circ}-160^{\circ} \mathrm{E}\right)$, (b) the southeastern Indian Ocean $\left(20^{\circ}-15^{\circ} \mathrm{S}, 100^{\circ}-110^{\circ} \mathrm{E}\right)$, and (c) the subtropical northern Atlantic $\left(25^{\circ}-35^{\circ} \mathrm{N}, 35^{\circ}-45^{\circ} \mathrm{W}\right)$. A single representative member of POGA raw data was calculated using the same time and the most adjacent position according to the EN4 raw data. The 7-yr smoothing mean of the EN4 SSS profiles (black solid line) and corresponding POGA SSS (red solid line) are superposed for comparison with the raw data. (d)-(f) As in (a)-(c), but with HIST (blue dots and black line) and POGA (gray dots and red line). (g) The locations of the three regions.

southeastern Indian Ocean due to Walker circulation changes (Fig. 1a). Strengthened Walker circulation in recent decades has led to increased precipitation in the ascending branch, causing SSS to decrease in the Maritime Continent and southeastern Indian Ocean. Meanwhile, the eastern Pacific SST cooling increased the zonal gradient of SST, leading to the westward shift of the Walker circulation. This shift led to less precipitation and higher SSS in the western tropical Pacific and ITCZ regions. These effects will be examined in more detail in section 5 .

Influenced by this strong decadal variability, the long-term POGA SSS trend was weaker in the western tropical Pacific and stronger in the southeastern Indian Ocean than in HIST over the 58 years of 1950-2008 (Figs. 2 and 3). Indeed, higher-frequency 
(a) POGA-HIST 1900-2014 SSS EOF-1st 28\%

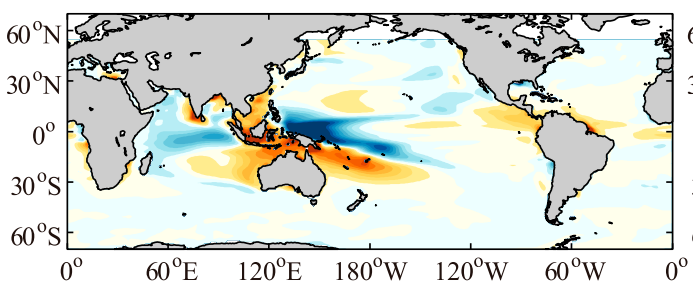

(b) EN4 Detrend 1900-2014 SSS EOF-1st 12\%

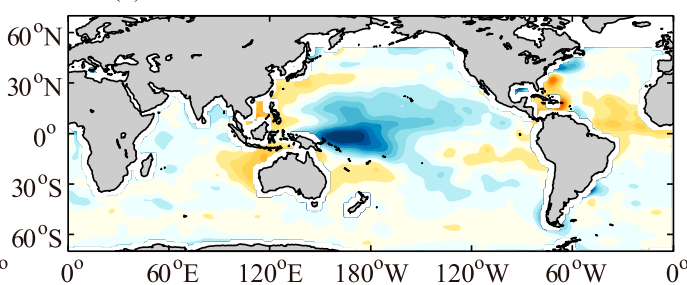

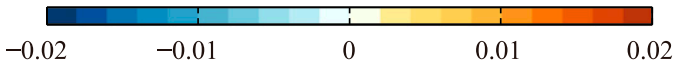

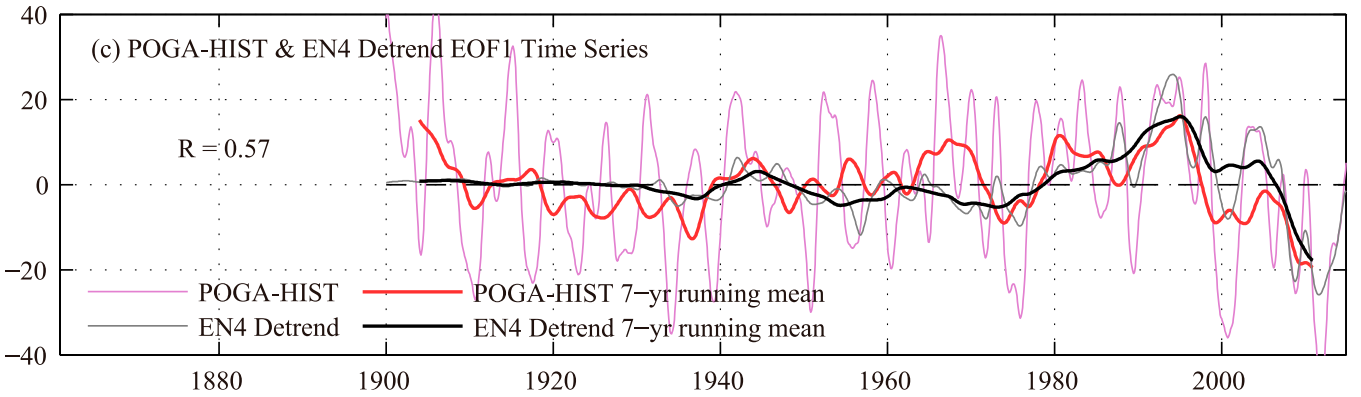

(d) ISHII Detrend 1945-2012 SSS EOF-1st 13\%

(e) ORAS4 Detrend 1958-2015 SSS EOF-1st 9\%
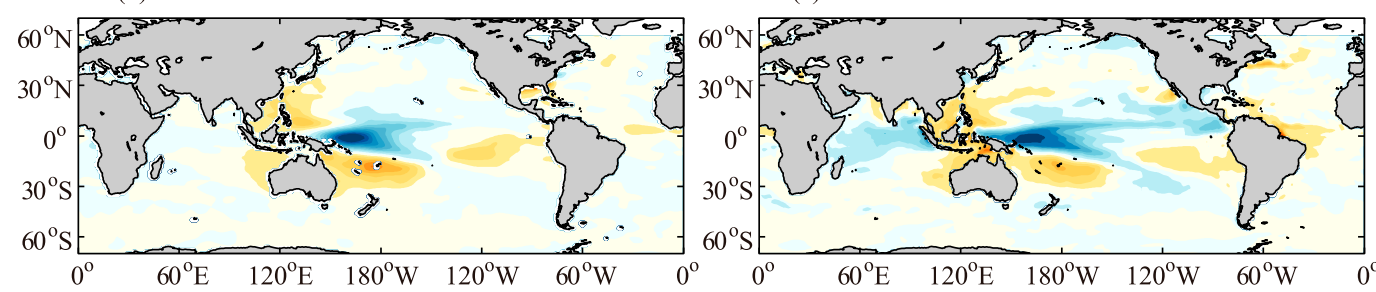

$\begin{array}{lllll}-0.02 & -0.01 & 0 & 0.01 & 0.02\end{array}$

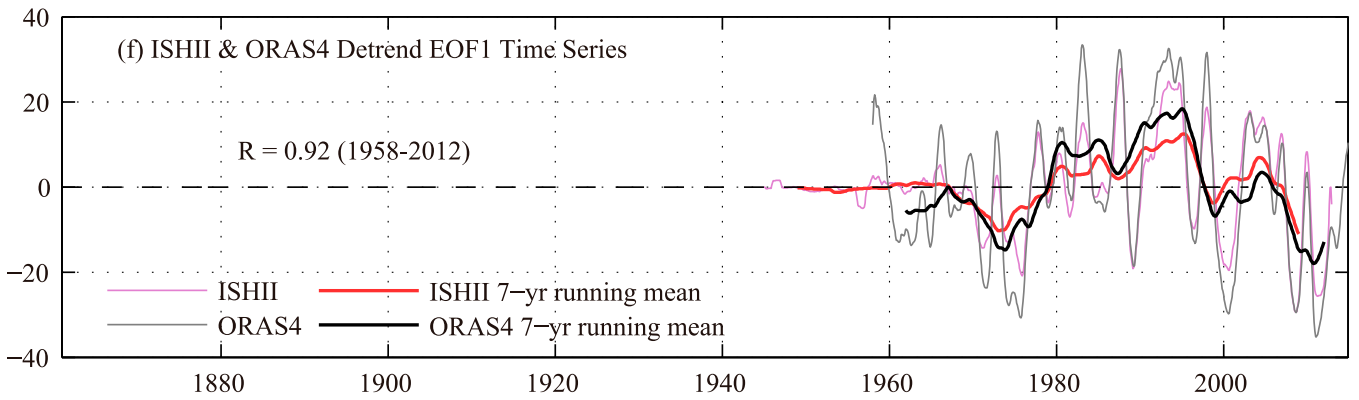

FIG. 4. The leading EOF modes of SSS in (a) POGA minus HIST and (b) EN4 Detrend (the linear trend is removed) for 1900-2014. (c) The principal component time series of SSS (in PSS) in POGA minus HIST (purple line, with red line for the 7-yr running mean) and EN4 Detrend (gray line, with black line for the 7-yr running mean). The correlation coefficient between POGA minus HIST and EN4 Detrend is 0.57 for 1900-2014. (d)-(f) As in (a)-(c), but for ISHII and ORAS4 Detrend datasets. The correlation coefficient between ISHII and ORAS4 Detrend is 0.92 for $1958-2012$.

variability, such as interannual variability, also played a role in the discrepancies among POGA, HIST, and the observations, according to a larger amplitude change of in situ profile data. These differences, mainly caused by the model biases in the mean state and the intensity of SSS changes (Fig. 3 and
Fig. S1), influenced the assessment of the SSS long-term trend. Additionally, owing to sparse and sporadic observations, the 7-yr smoothed fitting of EN4 in situ profile data was different from that of EN4 gridded products, especially before the 1980s in the western tropical Pacific and southeastern Indian Ocean 
(a) POGA - HIST SST EOF-1st 38\%
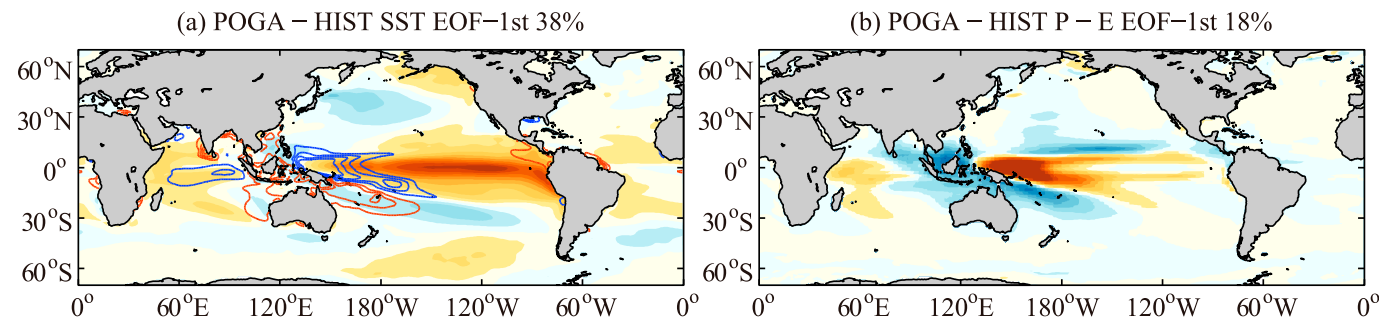

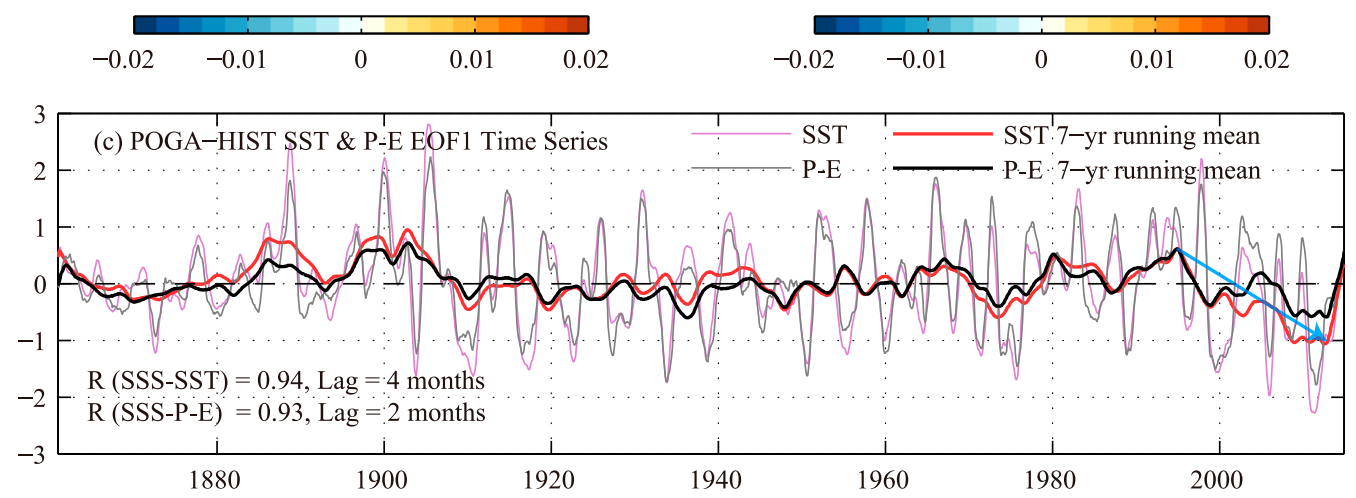

FIG. 5. The leading EOF modes of (a) SST (shading) and SSS (contours; red lines for positive and blue lines for negative at an interval of 0.005 ), and (b) $P$ minus $E$ in POGA minus HIST. (c) The normalized principal component time series of SST (purple line, with red line for 7-yr running mean) and $P$ minus $E$ (gray line, with black line for 7-yr running mean), superimposed with the 1993-2012 linear trend of the SST time series (blue arrow). The correlation coefficient between SST and SSS time series is 0.94 (the latter lags the former by 4 months). The correlation coefficient between $P$ minus $E$ and SSS time series is 0.93 (the latter lags the former by 2 months).

(Fig. 3 and Figs. S8-S10), reducing the reliability of assessing long-term SSS trends. All these factors have a significant influence on the investigation of SSS changes. In particular, the internal variability is large, contributing to the uncertainty in the long-term trend estimates at regional scales. This led us to reexamine the SSS trends over 1950-2008.

\section{Internal variability of SSS}

Despite the biases in the models, POGA can capture the internal variability and long-term SSS trends, allowing us to understand the SSS internal variability and its effect on the assessment of long-term trends under global warming. To distinguish the long-term trend in response to radiative forcing from internal variability, we subtracted the HIST ensemble mean from POGA to isolate anomalies associated with the internal variability in the eastern tropical Pacific for this section. In addition, this study removes the long-term linear trend to isolate the internal variability in the observations for this section.

Despite using the different methods, the leading EOF spatial pattern of POGA minus HIST is consistent with the observed pattern in the tropical regions (Fig. 4). The spatial pattern also agrees with the first EOF result of POGA (Fig. 1a), showing that SSS decreases in the ITCZ and SPCZ regions and the western tropical Indian Ocean, whereas it increases in the Maritime Continent, southeastern Indian Ocean, and tropical Atlantic, in the positive phase. The POGA minus HIST PC1 well reproduces the EN4 salinity record, including the interannual and decadal variability (the interannual and decadal correlations with observations are 0.52 and 0.57 , respectively), lending confidence in the POGA simulation. The POGA minus HIST PC1 is highly correlated with the Niño-3.4 SST and the IPO index, indicating that the method successfully isolates interannual to decadal internal variability. The year-by-year comparison between POGA and EN4 shows that the main discrepancy is a weak interannual variability in the EN4 results before the mid-1980s (Fig. 4c). This weak interannual variability is mainly caused by poor samplings from observations (Fig. 3). Since the twenty-first century, spatial and temporal coverage of observations have been enhanced, (e.g., the Argo program), partly improving the datasets in recent decades, but the paucity of observations prior to Argo precludes salinity internal variability assessments. For most areas in the Pacific Ocean, particularly in the Southern Hemisphere, data sparsity has considerably limited quantitative assessments. However, using the SST variability in the eastern tropical Pacific, POGA simulation provides new insights into studying the interannual to decadal variability of SSS since the 1900 s or even earlier.

To better understand the dynamic processes responsible for interannual to decadal variability of SSS and the role of airsea interactions, we evaluated the SST and surface freshwater flux $(P-E)$ anomalies associated with internal variability in the eastern tropical Pacific using the same methods as POGA minus HIST SSS EOF analysis (Fig. 5). An El Niño-like 
(a) POGA SST \& IPO index 1900-2014 Correlation

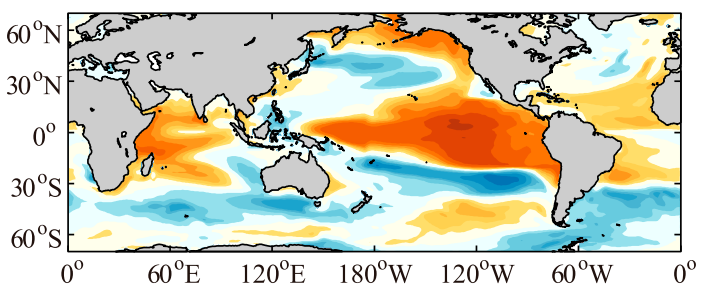

(c) POGA SSS \& IPO index 1900-2014 Correlation

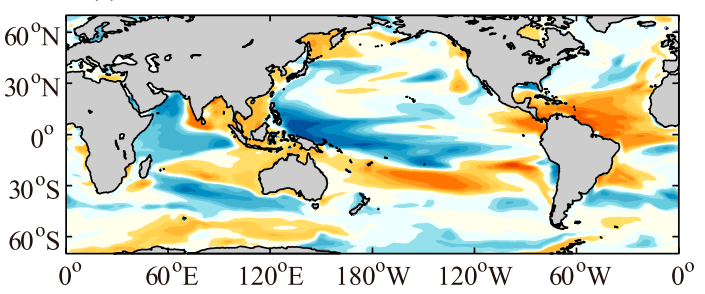

(e) ISHII SSS \& IPO index 1945-2012 Correlation

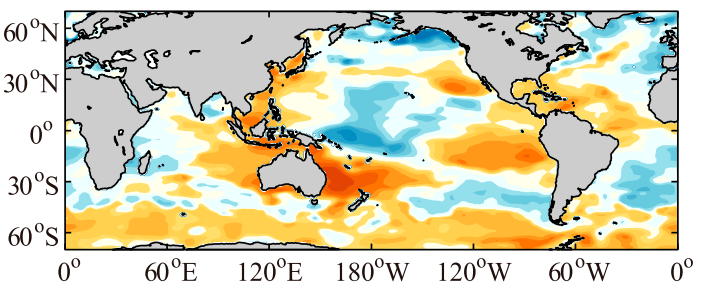

(b) POGA P-E \& IPO index 1900-2014 Correlation

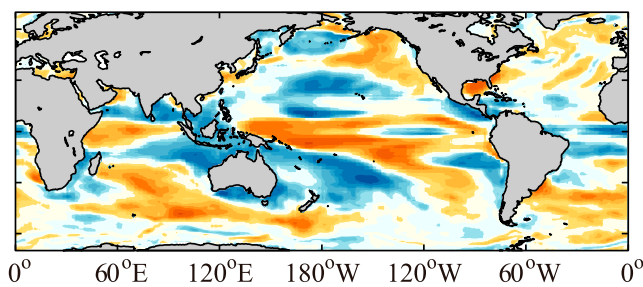

(d) EN4 SSS \& IPO index 1900-2014 Correlation

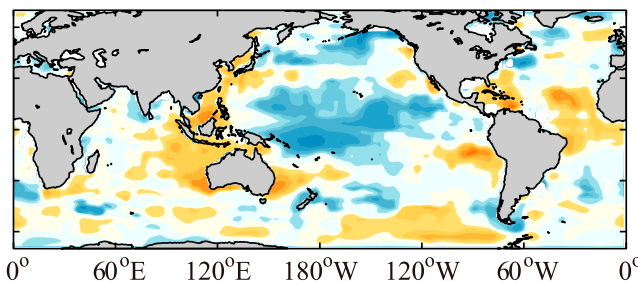

(f) ORAS4 SSS \& IPO index 1958-2014 Correlation

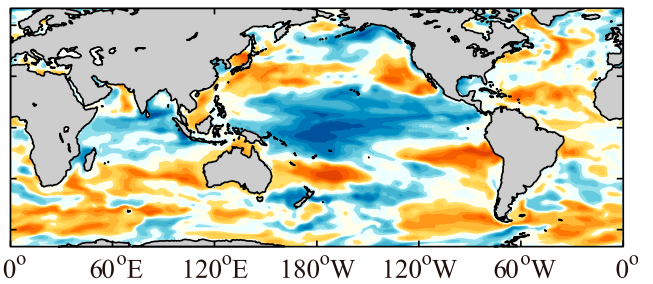

$-1-0.8-0.6-0.4-0.2 \quad 0 \quad 0.2 \quad 0.4 \quad 0.6 \quad 0.8 \quad 1$

FIG. 6. The correlation map between the IPO time series with (a) POGA SST, (b) POGA $P$ minus $E$ (former leads latter by 2 months), (c) POGA SSS (former leads latter by 4 months), (d) EN4 SSS (former leads latter by 4 months), (e) ISHII SSS (former leads latter by 4 months), and (f) ORAS4 SSS (former leads latter by 4 months).

pattern of SST, similar to typical ENSO or the IPO, emerges as expected (Fig. 5a), and the year-by-year and 7-yr smoothed time series of the SST are highly correlated with the Niño-3.4 and IPO index, respectively. These results demonstrate that the interannual and decadal variability of SST are mainly regulated by ENSO and the IPO, respectively (Fig. 5c). In particular, on the decadal scale, the SST pattern illustrates that the tropical Pacific SST is cooling in recent decades, offsetting the anthropogenic greenhouse effect and causing a slowdown of GMST warming, consistent with previous studies (Kosaka and Xie 2013, 2016; Meehl et al. 2016). This SST cooling in the eastern tropical Pacific enhances the SST zonal gradient, thus leading to the strengthening and westward shifting of the Pacific Walker circulation. It leads to more rainfall in the Maritime Continent and the southeastern Indian Ocean, and vice versa in the ITCZ and SPCZ regions and the western tropical Indian Ocean. These changes are well presented in the results of the POGA minus HIST surface freshwater fluxes in the first EOF mode (Fig. 5b), a pattern nearly opposite to the result of POGA minus HIST SSS (Fig. 4a). A strong correlation reveals that the tropical $P-E$ changes are directly linked to SST changes in the eastern tropical Pacific (Fig. 5c).
The correlation map with the IPO index further explicates the relationship between SST, surface freshwater fluxes, and SSS on the decadal scale (Fig. 6). It is clear that the spatial correlation patterns of POGA SST, $P-E$, SSS, and EN4 SSS are fairly similar to the results of their first leading EOF modes, respectively (Figs. 4a,b and 5a,b). Specifically, the SST exhibits an El Niño-like pattern, similar to the IPO mode. The mode of $P-E$ is nearly opposite to the POGA SSS pattern, negative in the ITCZ and SPCZ regions and western tropical Indian Ocean and positive in the Maritime Continent and southeastern Indian Ocean. These results illustrate that the IPO plays a dominant role in SST, $P-E$, and SSS changes on the decadal scale. The SST cooling (warming) in the equatorial eastern Pacific intensifies (weakens) the trade winds and the Walker circulation by increasing (decreasing) the SST zonal gradient. The Walker circulation further induces precipitation changes. Finally, the $P-E$ changes explain the SSS changes on the decadal scale. Notably, $P-E$ and salinity in the tropical Atlantic are opposite to those in the western tropical Pacific. Kosaka and Xie (2013) discussed the global influence of the tropical Pacific SST. We propose that SST changes in the eastern tropical Pacific influence Walker circulation in the tropical 


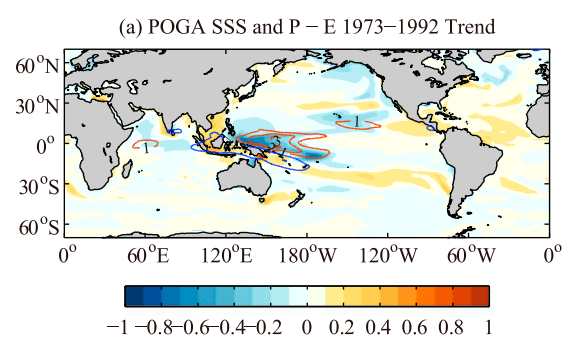

(b) POGA SSH and Currents 1973-1992 Trend

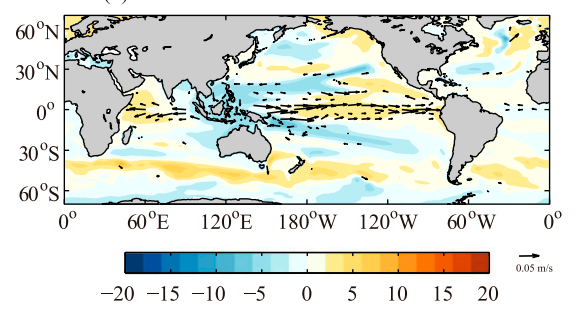

(c) POGA SLP and Winds 1973-1992 Trend

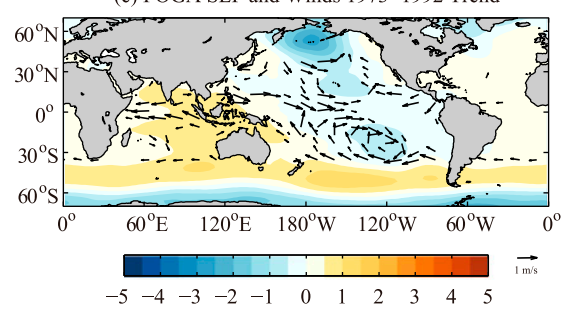

(d) POGA SSS and P - E 1993-2012 Trend

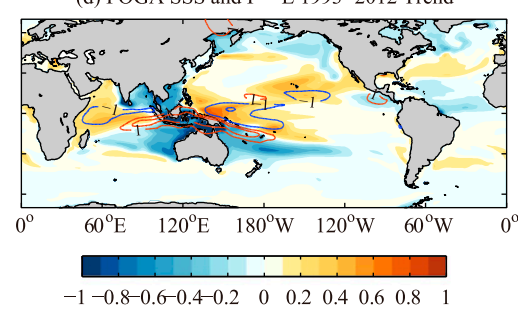

(e) POGA SSH and Currents 1993-2012 Trend

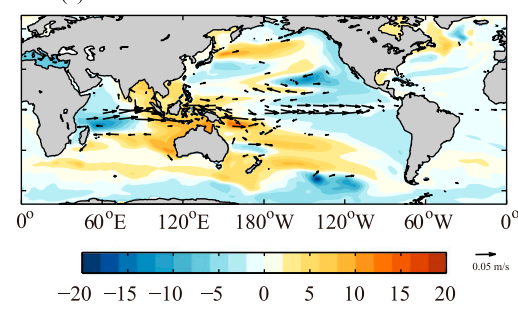

(f) POGA SLP and Winds 1993-2012 Trend

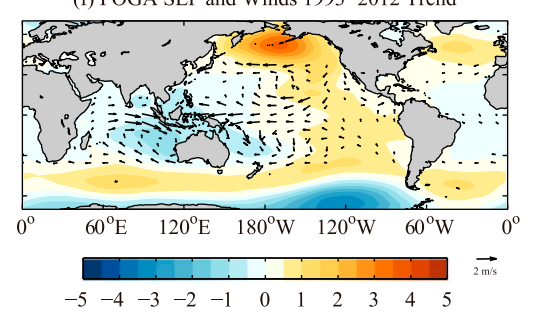

(g) Obs. SSS and P - E 1993-2012 Trend

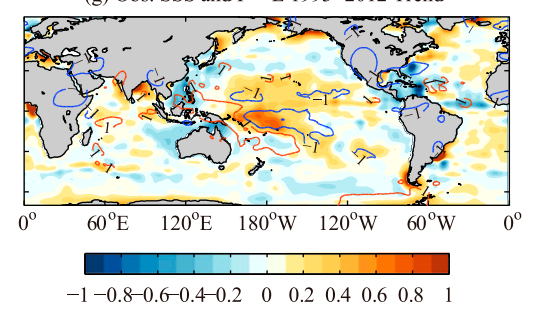

(h) Obs. SSH and Currents 1993-2012 Trend

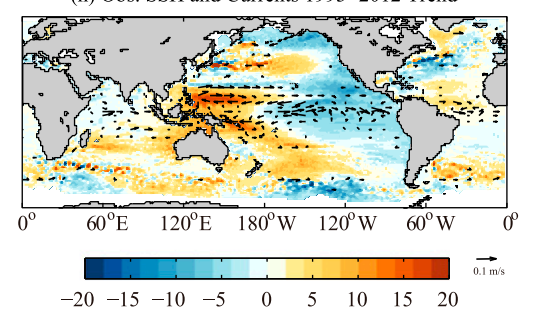

(i) Obs. SLP and Winds 1993-2012 Trend

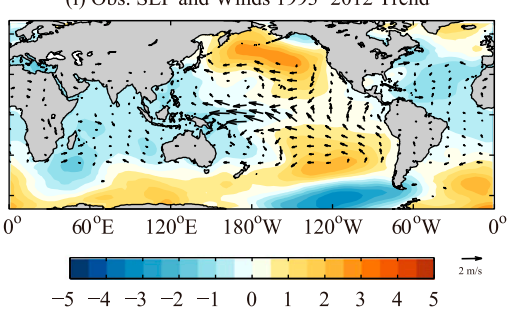

FIG. 7. 1973-92 20-yr linear trend of (a) POGA SSS (shading; PSS) and $P$ minus $E$ (contours at $1 \mathrm{~mm} \mathrm{day}^{-1}$ interval; red lines for positive and blue lines for negative), (b) POGA SSH (shading; $\mathrm{cm}$ ) and surface currents (vectors; $\mathrm{m} \mathrm{s}^{-1}$; current speeds lower than $0.02 \mathrm{~m} \mathrm{~s}^{-1}$ are omitted), and (c) POGA SLP (shading; hPa) and surface winds (vectors; $\mathrm{m} \mathrm{s}^{-1}$; wind speeds lower than $0.2 \mathrm{~m} \mathrm{~s}^{-1}$ are omitted). (d)-(f) As in (a)-(c), but for 1993-2012 20-yr linear trend. (g)-(i) As in (d)-(f), but for observation results.

Atlantic, leading to opposite changes in rainfall and salinity in the tropical Atlantic. A better understanding of interbasin ocean-atmosphere interaction will further improve our trend estimates in SSS in the future. In addition to $P-E$, the ocean dynamical processes play an important role in redistributing the SSS changes such as in the western boundary current regions of the North Pacific.

\section{Epoch differences}

We used the 1973-92 and 1993-2012 20-yr climatic trends to study the physical processes for decadal variability of SSS in the positive and negative trends of the IPO, respectively, and their effects on the estimation of SSS long-term trends under global warming (Fig. 7).

During the 1993-2012 IPO transition to its negative phase, when the tropical central and eastern Pacific SST cooled, the Pacific SLP zonal gradient and trade winds strengthened (Fig. 7f). Accelerated trade winds drove changes in sea level and ocean circulation. Specifically, the equatorial upwelling strengthened in the eastern Pacific, further cooling SST there. In the tropical Pacific, an intensified and westward shifting Walker circulation led to an increase in rainfall in the Maritime Continent and the southeastern Indian Ocean, whereas rainfall decreased in the ITCZ and SPCZ regions and the western and central equatorial Indian Ocean. These changes in rainfall eventually led to a nearly opposite spatial pattern of salinity changes. Except for some biases, such as the intensity of sea level change and position displacement of the SSS changes, the simulation results agree with the observations, providing new insights into these processes.

Changes opposite to those for 1993-2012 occurred during the 1973-92 period (Figs. 7a-c), indicating strong interdecadal internal variability. With the decrease in the Pacific SLP gradient, warming accelerated in the tropical central and eastern Pacific SST at the IPO positive phase, causing further weakening of trade winds. Rainfall decreased in the Maritime Continent and increased in the ITCZ and SPCZ regions owing to the weakening of the Walker circulation and the eastward shift in its ascending branch. The SSS captured the rainfall pattern in the tropical Pacific and Indian Ocean, allowing us to better understand the water cycle changes. Although precipitation, evaporation, and other variables are not directly observed throughout the 1973-92 period, the SSS trend from observations is consistent with the POGA SSS pattern during this period (Fig. S11), supporting our simulation results. This indicates that salinity is a good indicator for assessing the water cycle.

Previous studies suggested that the recent global warming hiatus is linked to the negative phases of the IPO, illustrating 

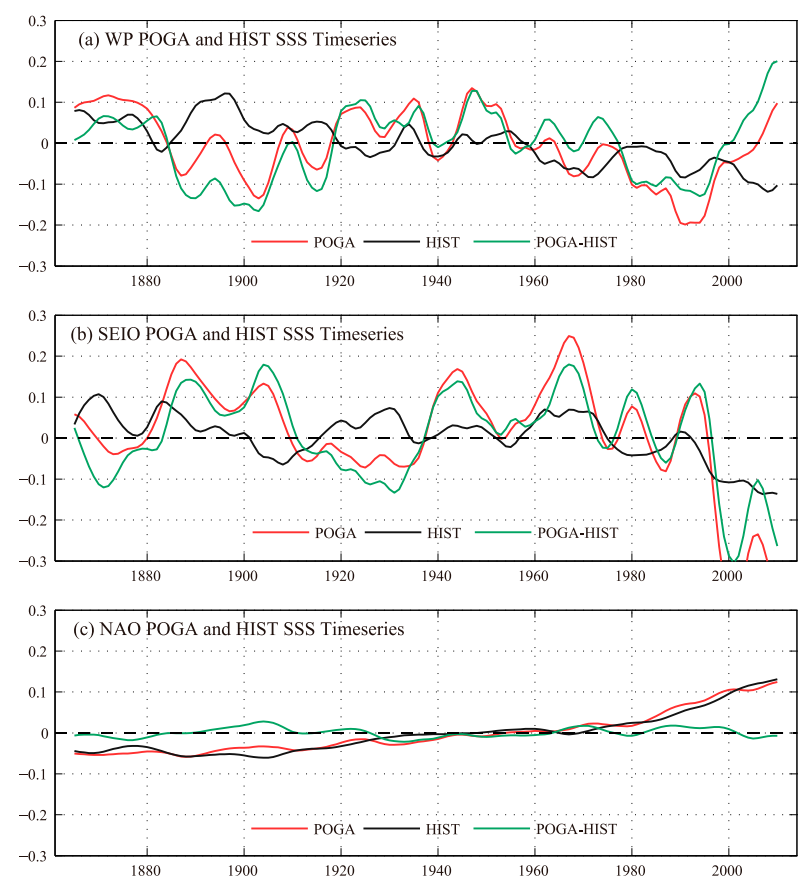

FIG. 8. POGA (red line), HIST (black line), and POGA minus HIST (green line) 7-yr smoothed SSS anomalies (PSS) in (a) the western tropical Pacific $\left(10^{\circ} \mathrm{S}-10^{\circ} \mathrm{N}, 150^{\circ}-170^{\circ} \mathrm{E}\right)$, (b) southeastern Indian Ocean $\left(20^{\circ}-10^{\circ} \mathrm{S}, 100^{\circ}-120^{\circ} \mathrm{E}\right)$, and (c) the subtropical northern Atlantic $\left(20^{\circ}-40^{\circ} \mathrm{N}, 30^{\circ}-60^{\circ} \mathrm{W}\right)$. POGA minus HIST represents the internal variability affected by the eastern tropical Pacific SST.

that the interdecadal internal variability could modulate the global warming rate over a decade or an even longer period. Therefore, we further studied SSS internal variability and its effect on the SSS long-term change rate. In contrast to the results of previous studies, our results show that recent decadal SSS changes play an important role in the assessment of the long-term SSS trends. Cravatte et al. (2009) showed that water warmer than $28.5^{\circ} \mathrm{C}$ in the western Pacific warm pool freshens by approximately 0.22 PSS over 1970-2003, similar to the EN4 and POGA results (Fig. S12). However, for the 1950-2012 period, the EN4 and POGA SSS in the western Pacific warm pool both decreased by approximately 0.1 PSS, only half of the SSS change during 1970-2003. The excessively high SSS trend during 1970-2003 was mainly caused by decadal variability. In particular, a positive IPO intensified the decrease in SSS during 1973-92, whereas the phase transition of IPO during 1993-2012 slowed down the longterm SSS trends. In addition, this internal variability also affected the SSS changes in the southeastern Indian Ocean, as mentioned earlier.

To quantify the contribution from the internal decadal variability associated with the IPO to the long-term trends in SSS, we calculated the changes in the 7-yr running-mean SSS in POGA, HIST, and POGA minus HIST between 1973-92, 1993-2012, and 1950-2012 in the western tropical Pacific and southeastern Indian Ocean (Fig. 8 and Table 1). Specifically, SSS increased and decreased by approximately 0.4 PSS in the western tropical Pacific and southeastern Indian Ocean during 1993-2012, respectively (Table 1). The magnitude of this SSS internal decadal variability is comparable to or even larger than the long-term trend over the 63 years of 1950-2012, drastically reducing the SSS long-term trend in the western tropical Pacific as the IPO shifted into a negative phase over the past 20 years (Table 1). For those 63 years, the internal variability increased the SSS by approximately 0.04 PSS in the western tropical Pacific, offsetting the 63-yr SSS trend in HIST by approximately $40 \%$, whereas the SSS decreased by approximately 0.3 PSS in the southeastern Indian Ocean, considerably amplifying the HIST 63-yr trend.

In agreement with previous results in section 4, the effect of the IPO led to a stronger SSS trend in the western tropical Pacific and a weaker trend in the southeastern Indian Ocean, which explains the regional discrepancy between POGA and HIST presented in Fig. 2. Therefore, the effect of internal variability needs to be considered to obtain a more accurate attribution for the long-term SSS trends. In other words, estimating over a longer period, such as 100 years, may be an effective method of reducing the influence of internal variability on the SSS trend estimate.

\section{Conclusions with discussion}

This study investigated the internal variability of SSS under global warming for inferring water cycle changes. POGA and historical simulations were used to distinguish between internal variability and long-term trends in response to global warming. Compared with the observations, the POGA simulation not only successfully reproduced the long-term SSS trend, but also captured the SSS internal interannual and decadal variability. On a global scale, in agreement with previous studies, both POGA and HIST revealed that salty regions, such as the Atlantic and subtropical Pacific, have become saltier owing to the reduced rainfall and enhanced evaporation. On a

TABLE 1. POGA, HIST, and POGA - HIST SSS linear trends (PSS over the period) in the western tropical Pacific $\left(10^{\circ} \mathrm{S}-10^{\circ} \mathrm{N}, 150^{\circ}-\right.$ $\left.170^{\circ} \mathrm{E}\right)$ and southeastern Indian Ocean $\left(20^{\circ}-10^{\circ} \mathrm{S}, 100^{\circ}-120^{\circ} \mathrm{E}\right)$ during $1950-2012,1973-92$, and 1993-2012.

\begin{tabular}{|c|c|c|c|c|c|c|}
\hline \multirow[b]{2}{*}{ Expt name } & \multicolumn{3}{|c|}{ Western tropical Pacific } & \multicolumn{3}{|c|}{ Southeastern Indian Ocean } \\
\hline & 1950-2012 trend & $1973-92$ trend & 1993-2012 trend & 1950-2012 trend & $1973-92$ trend & 1993-2012 trend \\
\hline POGA & -0.06 & -0.24 & 0.30 & -0.48 & 0.04 & -0.48 \\
\hline HIST & -0.10 & -0.04 & -0.10 & -0.18 & 0.03 & -0.08 \\
\hline POGA - HIST & 0.04 & -0.20 & 0.40 & -0.30 & 0.01 & -0.40 \\
\hline$(\mathrm{POGA}-\mathrm{HIST}) / \mathrm{HIST}$ & $-40 \%$ & $500 \%$ & $-400 \%$ & $167 \%$ & $33 \%$ & $500 \%$ \\
\hline
\end{tabular}


regional scale, the SSS trend was found to be related to the moisture increase and Walker circulation weakening and shift under global warming in the tropical Indo-Pacific (Chadwick et al. 2013; Ma et al. 2018). Specifically, the weakening of the Walker circulation led to a decrease in rainfall around the Maritime Continent, partially offsetting the effect of moisture increase. In addition, the Walker circulation shifts in convective regions associated with SST warming patterns led to significantly increased precipitation in the western Pacific (Xie et al. 2010). However, SSS change over the past 20 years led to a discrepancy in the long-term SSS trend between POGA and HIST in the western tropical Pacific and southeastern Indian Ocean. The magnitude of this internal variability was as large as the SSS trend over the 63-yr 1950-2012 period, rendering the estimate of the forced trend uncertain.

The POGA reproduces the SSS interannual and decadal variability impacted by the eastern tropical Pacific SST, enabling the study of regional SSS internal variability. On the decadal scale, the result shows that the SSS variability is related to the IPO. During the negative IPO trend, SST cooling in the eastern tropical Pacific strengthened the Walker circulation. The Walker circulation change caused rainfall to increase in the Maritime Continent and southeastern Indian Ocean and decrease in the ITCZ and SPCZ regions. These processes are evidently reflected in the SSS changes, which affected the regional estimate of the SSS trend in response to global warming. Specifically, the IPO led to a $\sim 40 \%$ offset of the SSS response trend in the western tropical Pacific and $\sim 170 \%$ enhancement in the trend in the southeastern Indian Ocean. A better understanding of SSS internal variability will improve the accuracy of estimating the long-term SSS trends in the future.

Although this paper discusses the effect of the internal variability on the SSS changes, especially associated with the IPO, the physical mechanism of the IPO remains unclear. Many studies have shown that the tropical Atlantic plays a key role in atmospheric Walker circulation changes over the recent decades, indicating the complexity of the mechanism with the interbasin impact rather than an independent influence from the Pacific (Li et al. 2015; McGregor et al. 2014). Such Atlantic decadal variability may also have affected the SSS trend, especially over the tropical Atlantic, but POGA cannot incorporate this effect. Thus, quantifying the influence of other decadal variabilities will further improve our understanding and attribution for the SSS trends.

Salinity is a useful metric for tracking changes in the hydrologic cycle. However, ocean dynamics affect the salinity distribution as an additional important factor (Du et al. 2019; Liu et al. 2019; Ponte and Vinogradova 2016; Vinogradova and Ponte 2013, 2017; Yu 2011). Ocean advection and mixing processes redistribute the salinity pattern to achieve a new balance. For instance, a few studies have investigated the role of $P-E$ as a driver of surface and subsurface salinity changes (Durack et al. 2012; Lago et al. 2016; Williams et al. 2006, 2007, 2010). They showed that the three-dimensional salinity gradients are enhanced if $P-E$ surface fluxes are amplified at the surface. This paper focuses on the relationship between near-surface salinity and freshwater flux changes; however, the role of ocean dynamic processes requires further investigation to understand the water cycle changes in the future. Some studies have found that errors in the observations and statistical assessments could yield different results. For instance, Argo measurements of SSS have a positive bias of 0.1-0.2 PSS, compared to satellite observations in the tropical Indian Ocean, which may be attributed to the different depths of SSS observed by the satellite and Argo (Du and Zhang 2015). The satellite measures the skin salinity, whereas Argo floats measure the salinity at a $\sim 5-\mathrm{m}$ depth, which is more representative of the mixed layer salinity. Data users should be aware of what their data products represent, because most products are not directly comparable. For merging these data, the biases from the Argo, satellite, and other observations should be corrected. Moreover, the statistical analysis method, especially the long-term linear trend, introduces errors. Although long-term linear trends are calculated over a sufficiently long period to suppress internal variability, a more comprehensive method needs to be developed to further reduce the potential errors.

Acknowledgments. We acknowledge NOAA Physical Sciences Division for hosting the OISST and ERSST products (https:/www.esrl.noaa.gov/psd/data/gridded/). The EN4, ISHII, and ORAS4 salinity were provided by Met Office Hadley Centre (https://www.metoffice.gov.uk/hadobs/en4/), the Computational and Information Systems Laboratory at NCAR (https://rda.ucar.edu/datasets/ds285.3/), and the ECMWF (https:// www.ecmwf.int/en/research/climate-reanalysis/ocean-reanalysis), respectively. GPCP precipitation and evaporation were obtained from NASA/GSFC (http://precip.gsfc.nasa.gov) and the OAFlux project (http://oaflux.whoi.edu/), respectively. The surface wind and SLP were available from ECMWF interim reanalysis (ERAInterim; https://www.ecmwf.int/en/forecasts/datasets/reanalysisdatasets/era-interim). OSCAR currents were provided by NOAA's Ocean Surface Current Analyses Real Time (https:// podaac.jpl.nasa.gov/dataset/OSCAR_L4_OC_third-deg). The SSHA was provided by the AVISO (https://www.aviso.altimetry.fr/ en/data/data-access.html). The work at SCSIO/CAS is supported by the National Natural Science Foundation of China (42090042, 41525019, and 41830538), the Chinese Academy of Sciences (XDA15020901, 133244KYSB20190031, ZDRW-XH-2019-2), the State Oceanic Administration of China (GASI-IPOVAI-02), and the Southern Marine Science and Engineering Guangdong Laboratory (Guangzhou) (GML2019ZD0303, 2019BT02H594). Y.K. is supported by JSPS KAKENHI Grants JP18H01278, JP18H01281, and JP19H05703, the Integrated Research Program for Advancing Climate Models (JPMXD0717935457), and the Belmont Forum CRA "InterDec".

\section{REFERENCES}

Adler, R. F., and Coauthors, 2003: The version-2 Global Precipitation Climatology Project (GPCP) monthly precipitation analysis (1979-present). J. Hydrometeor., 4, 1147-1167, https://doi.org/ 10.1175/1525-7541(2003)004<1147:TVGPCP >2.0.CO;2.

Balmaseda, M. A., K. Mogensen, and A. T. Weaver, 2013: Evaluation of the ECMWF ocean reanalysis system ORAS4. Quart. J. Roy. Meteor. Soc., 139, 1132-1161, https://doi.org/10.1002/qj.2063.

Bonjean, F., and G. S. E. Lagerloef, 2002: Diagnostic model and analysis of the surface currents in the tropical Pacific Ocean. J. Phys. Oceanogr., 32, 2938-2954, https://doi.org/10.1175/ 1520-0485(2002)032<2938:DMAAOT>2.0.CO;2. 
Boyer, T. P., S. Levitus, J. I. Antonov, R. A. Locarnini, and H. E. Garcia, 2005: Linear trends in salinity for the World Ocean, 1955-1998. Geophys. Res. Lett., 32, L01604, https://doi.org/ 10.1029/2004GL021791.

Chadwick, R., I. Boutle, and G. Martin, 2013: Spatial patterns of precipitation change in CMIP5: Why the rich do not get richer in the tropics. J. Climate, 26, 3803-3822, https://doi.org/ 10.1175/JCLI-D-12-00543.1.

— , P. Good, T. Andrews, and G. Martin, 2014: Surface warming patterns drive tropical rainfall pattern responses to $\mathrm{CO}_{2}$ forcing on all timescales. Geophys. Res. Lett., 41, 610-615, https://doi.org/10.1002/2013GL058504.

Chen, G., J. Norris, J. D. Neelin, J. Lu, L. R. Leung, and K. Sakaguchi, 2019: Thermodynamic and dynamic mechanisms for hydrological cycle intensification over the full probability distribution of precipitation events. J. Atmos. Sci., 76, 497-516, https://doi.org/10.1175/JAS-D-18-0067.1.

Chou, C., and J. D. Neelin, 2004: Mechanisms of global warming impacts on regional tropical precipitation. J. Climate, 17, 2688-2701, https://doi.org/10.1175/1520-0442(2004)017<2688: MOGWIO $>2.0 . \mathrm{CO} ; 2$.

,-- , C.-A. Chen, and J.-Y. Tu, 2009: Evaluating the "richget-richer" mechanism in tropical precipitation change under global warming. J. Climate, 22, 1982-2005, https://doi.org/ 10.1175/2008JCLI2471.1.

Church, J. A., and N. J. White, 2006: A 20th century acceleration in global sea-level rise. Geophys. Res. Lett., 33, L01602, https:// doi.org/10.1029/2005GL024826.

- — - R. Coleman, K. Lambeck, and J. X. Mitrovica, 2004: Estimates of the regional distribution of sea level rise over the 1950-2000 period. J. Climate, 17, 2609-2625, https://doi.org/ 10.1175/1520-0442(2004)017<2609:EOTRDO>2.0.CO;2.

Cravatte, S., T. Delcroix, D. X. Zhang, M. McPhaden, and J. Leloup, 2009: Observed freshening and warming of the western Pacific warm pool. Climate Dyn., 33, 565-589, https:// doi.org/10.1007/s00382-009-0526-7.

Curry, R., B. Dickson, and I. Yashayaev, 2003: A change in the freshwater balance of the Atlantic Ocean over the past four decades. Nature, 426, 826-829, https://doi.org/10.1038/nature02206.

Dai, A., and C. E. Bloecker, 2019: Impacts of internal variability on temperature and precipitation trends in large ensemble simulations by two climate models. Climate Dyn., 52, 289-306, https://doi.org/10.1007/s00382-018-4132-4.

Dee, D. P., and Coauthors, 2011: The ERA-Interim reanalysis: Configuration and performance of the data assimilation system. Quart. J. Roy. Meteor. Soc., 137, 553-597, https://doi.org/ 10.1002/qj.828.

Delworth, T. L., and Coauthors, 2006: GFDL's CM2 global coupled climate models. Part I: Formulation and simulation characteristics. J. Climate, 19, 643-674, https://doi.org/10.1175/ JCLI3629.1.

Diffenbaugh, N. S., J. S. Pal, R. J. Trapp, and F. Giorgi, 2005: Fine-f extreme events to global climate change. Proc. Natl. Acad. Sci. USA, 102, 152774-152778, https://doi.org/10.1073/pnas.0506042102.

Dong, B., and A. G. Dai, 2015: The influence of the interdecadal Pacific oscillation on temperature and precipitation over the globe. Climate Dyn., 45, 2667-2681, https://doi.org/10.1007/s00382-015-2500-x.

Dong, B. W., and R. Y. Lu, 2013: Interdecadal enhancement of the Walker circulation over the tropical Pacific in the late 1990s. Adv. Atmos. Sci., 30, 247-262, https://doi.org/10.1007/s00376012-2069-9.

Du, Y., and Y. H. Zhang, 2015: Satellite and Argo observed surface salinity variations in the tropical Indian Ocean and their association with the Indian Ocean dipole mode. J. Climate, 28, 695-713, https://doi.org/10.1175/JCLI-D-14-00435.1.

- - _ M. Meng, T. Wang, N. Zhang, and S. Wijffels, 2015: Decadal trends of the upper ocean salinity in the tropical IndoPacific since mid-1990s. Sci. Rep., 5, 16050, https://doi.org/ 10.1038/srep16050.

— - — , and J. C. Shi, 2019: Relationship between sea surface salinity and ocean circulation and climate change. Sci. China Earth Sci., 62, 771-782, https://doi.org/10.1007/s11430-0189276-6.

Dukhovskoy, D. S., and Coauthors, 2016: Greenland freshwater pathways in the sub-Arctic seas from model experiments with passive tracers. J. Geophys. Res. Oceans, 121, 877-907, https:// doi.org/10.1002/2015JC011290.

Durack, P. J., 2015: Ocean salinity and the global water cycle. Oceanography, 28, 20-31, https://doi.org/10.5670/oceanog.2015.03.

— ities and their relationship to broad-scale warming. J. Climate, 23, 4342-4362, https://doi.org/10.1175/2010JCLI3377.1.

_ — - and R. J. Matear, 2012: Ocean salinities reveal strong global water cycle intensification during 1950 to 2000. Science, 336, 455-458, https://doi.org/10.1126/science.1212222.

Emori, S., and S. J. Brown, 2005: Dynamic and thermodynamic changes in mean and extreme precipitation under changed climate. Geophys. Res. Lett., 32, L17706, https://doi.org/ 10.1029/2005GL023272.

England, M. H., and Coauthors, 2014: Recent intensification of wind-driven circulation in the Pacific and the ongoing warming hiatus. Nat. Climate Change, 4, 222-227, https://doi.org/ 10.1038/nclimate2106.

Fu, Q., C. M. Johanson, J. M. Wallace, and T. Reichler, 2006: Enhanced mid-latitude tropospheric warming in satellite measurements. Science, 312, 1179, https://doi.org/10.1126/science. 1125566.

Fyfe, J. C., and Coauthors, 2016: Making sense of the early-2000s warming slowdown. Nat. Climate Change, 6, 224-228, https:// doi.org/10.1038/nclimate2938.

Good, S. A., M. J. Martin, and N. A. Rayner, 2013: EN4: Quality controlled ocean temperature and salinity profiles and monthly objective analyses with uncertainty estimates. J. Geophys. Res. Oceans, 118, 6704-6716, https://doi.org/10.1002/2013JC009067.

Gordon, A. L., and C. F. Giulivi, 2008: Sea surface salinity trends over fifty years within the subtropical North Atlantic. Oceanography, 21, 20-29, https://doi.org/10.5670/oceanog.2008.64.

Hasegawa, T., K. Ando, I. Ueki, K. Mizuno, and S. Hosoda, 2013: Upper-ocean salinity variability in the tropical Pacific: Case study for quasi-decadal shift during the 2000s using TRITON buoys and Argo floats. J. Climate, 26, 8126-8138, https:// doi.org/10.1175/JCLI-D-12-00187.1.

Held, I. M., and B. J. Soden, 2006: Robust responses of the hydrological cycle to global warming. J. Climate, 19, 5686-5699, https://doi.org/10.1175/JCLI3990.1.

Helm, K. P., N. L. Bindoff, and J. A. Church, 2010: Changes in the global hydrological-cycle inferred from ocean salinity. Geophys. Res. Lett., 37, L18701, https://doi.org/10.1029/2010GL044222.

Henley, B. J., J. Gergis, D. J. Karoly, S. Power, J. Kennedy, and C. K. Folland, 2015: A tripole index for the interdecadal Pacific oscillation. Climate Dyn., 45, 3077-3090, https://doi.org/10.1007/ s00382-015-2525-1.

Hosoda, S., T. Suga, N. Shikama, and K. Mizuno, 2009: Global surface layer salinity change detected by Argo and its implication for hydrological cycle intensification. J. Oceanogr., $\mathbf{6 5}$, 579-586, https://doi.org/10.1007/s10872-009-0049-1. 
Hu, S. N., and A. V. Fedorov, 2019: Indian Ocean warming can strengthen the Atlantic meridional overturning circulation. Nat. Climate Change, 9, 747-751, https://doi.org/10.1038/s41558-0190566-x.

Huang, P., S. P. Xie, K. M. Hu, G. Huang, and R. H. Huang, 2013: Patterns of the seasonal response of tropical rainfall to global warming. Nat. Geosci., 6, 357-361, https://doi.org/10.1038/ ngeo1792.

Ishii, M., M. Kimoto, K. Sakamoto, and S. I. Iwasaki, 2006: Steric sea level changes estimated from historical ocean subsurface temperature and salinity analyses. J. Oceanogr., 62, 155-170, https://doi.org/10.1007/s10872-006-0041-y.

Khan, S. A., and Coauthors, 2014: Sustained mass loss of the northeast Greenland ice sheet triggered by regional warming. Nat. Climate Change, 4, 292-299, https://doi.org/10.1038/nclimate2161.

Kosaka, Y., and S.-P. Xie, 2013: Recent global-warming hiatus tied to equatorial Pacific surface cooling. Nature, 501, 403-407, https://doi.org/10.1038/nature12534.

— and - 2016: The tropical Pacific as a key pacemaker of the variable rates of global warming. Nat. Geosci., 9, 669-673, https://doi.org/10.1038/ngeo2770.

Lago, V., S. E. Wijffels, P. J. Durack, J. A. Church, N. L. Bindoff, and S. J. Marsland, 2016: Simulating the role of surface forcing on observed multidecadal upper-ocean salinity changes. J. Climate, 29, 5575-5588, https://doi.org/10.1175/JCLI-D-15-0519.1.

Lehner, F., C. C. Raible, D. Hofer, and T. F. Stocker, 2012: The freshwater balance of polar regions in transient simulations from 1500 to $2100 \mathrm{AD}$ using a comprehensive coupled climate model. Climate Dyn., 39, 347-363, https://doi.org/10.1007/ s00382-011-1199-6.

L'Heureux, M. L., S. Lee, and B. Lyon, 2013: Recent multidecadal strengthening of the Walker circulation across the tropical Pacific. Nat. Climate Change, 3, 571-576, https://doi.org/ 10.1038/nclimate1840.

Li, X., S.-P. Xie, S. T. Gille, and C. Yoo, 2015: Atlantic-induced pantropical climate change over the past three decades. Nat. Climate Change, 6, 275-279, https://doi.org/10.1038/nclimate2840.

Liu, C., X. Liang, R. M. Ponte, N. Vinogradova, and O. Wang, 2019: Vertical redistribution of salt and layered changes in global ocean salinity. Nat. Commun., 10, 3445, https://doi.org/ 10.1038/s41467-019-11436-x.

Ma, J., and S.-P. Xie, 2013: Regional patterns of sea surface temperature change: A source of uncertainty in future projections of precipitation and atmospheric circulation. J. Climate, 26, 2482-2501, https://doi.org/10.1175/JCLI-D-12-00283.1.

—, R. Chadwick, K.-H. Seo, C. Dong, G. Huang, G. R. Foltz, and J. H. Jiang, 2018: Responses of the tropical atmospheric circulation to climate change and connection to the hydrological cycle. Annu. Rev. Earth Planet. Sci., 46, 549-580, https:// doi.org/10.1146/annurev-earth-082517-010102.

Ma, S. M., and T. J. Zhou, 2016: Robust strengthening and westward shift of the tropical Pacific Walker circulation during 1979-2012: A comparison of 7 sets of reanalysis data and 26 CMIP5 models. J. Climate, 29, 3097-3118, https://doi.org/ 10.1175/JCLI-D-15-0398.1.

McGregor, S., A. Timmermann, M. F. Stuecker, M. H. England, M. Merrifield, F. F. Jin, and Y. Chikamoto, 2014: Recent Walker circulation strengthening and Pacific cooling amplified by Atlantic warming. Nat. Climate Change, 4, 888-892, https:// doi.org/10.1038/nclimate2330.

Medhaug, I., M. B. Stolpe, E. M. Fischer, and R. Knutti, 2017: Reconciling controversies about the 'global warming hiatus.' Nature, 545, 41-47, https://doi.org/10.1038/nature22315.
Meehl, G. A., A. X. Hu, J. M. Arblaster, J. Fasullo, and K. E. Trenberth, 2013: Externally forced and internally generated decadal climate variability associated with the interdecadal Pacific oscillation. J. Climate, 26, 7298-7310, https://doi.org/ 10.1175/JCLI-D-12-00548.1.

,-- B. D. Santer, and S. P. Xie, 2016: Contribution of the Interdecadal Pacific Oscillation to twentieth-century global surface temperature trends. Nat. Climate Change, 6, 10051008, https://doi.org/10.1038/nclimate3107.

Norris, J., G. Chen, and J. D. Neelin, 2019: Thermodynamic versus dynamic controls on extreme precipitation in a warming climate from the Community Earth System Model large ensemble. J. Climate, 32, 1025-1045, https://doi.org/10.1175/JCLI-D-18-0302.1.

Nummelin, A., M. Ilicak, C. Li, and L. H. Smedsrud, 2016: Consequences of future increased Arctic runoff on Arctic Ocean stratification, circulation, and sea ice cover. J. Geophys. Res. Oceans, 121, 617-637, https://doi.org/10.1002/2015JC011156.

Ponte, R. M., and N. T. Vinogradova, 2016: An assessment of basic processes controlling mean surface salinity over the global ocean. Geophys. Res. Lett., 43, 7052-7058, https://doi.org/ 10.1002/2016GL069857.

Reynolds, R. W., N. A. Rayner, T. M. Smith, D. C. Stokes, and W. Q. Wang, 2002: An improved in situ and satellite SST analysis for climate. J. Climate, 15, 1609-1625, https://doi.org/ 10.1175/1520-0442(2002)015<1609:AIISAS > 2.0.CO;2.

Schmitt, R. W., 2008: Salinity and the global water cycle. Oceanography, 21, 12-19, https://doi.org/10.5670/oceanog.2008.63.

Seager, R., N. Naik, and G. A. Vecchi, 2010: Thermodynamic and dynamic mechanisms for large-scale changes in the hydrological cycle in response to global warming. J. Climate, $\mathbf{2 3}$, 4651-4668, https://doi.org/10.1175/2010JCLI3655.1.

Seidel, D. J., Q. Fu, W. J. Randel, and T. J. Reichler, 2008: Widening of the tropical belt in a changing climate. Nat. Geosci., 1, 21-24, https://doi.org/10.1038/ngeo.2007.38.

Skliris, N., R. Marsh, S. A. Josey, S. A. Good, C. L. Liu, and R. P. Allan, 2014: Salinity changes in the World Ocean since 1950 in relation to changing surface freshwater fluxes. Climate Dyn., 43, 709-736, https://doi.org/10.1007/s00382-014-2131-7.

Taylor, K. E., R. J. Stouffer, and G. A. Meehl, 2012: An overview of CMIP5 and the experiment design. Bull. Amer. Meteor. Soc., 93, 485-498, https://doi.org/10.1175/BAMS-D-11-00094.1.

Terray, L., L. Corre, S. Cravatte, T. Delcroix, G. Reverdin, and A. Ribes, 2012: Near-surface salinity as nature's rain gauge to detect human influence on the tropical water cycle. J. Climate, 25, 958-977, https://doi.org/10.1175/JCLI-D-10-05025.1.

Tokinaga, H., S. P. Xie, C. Deser, Y. Kosaka, and Y. M. Okumura, 2012: Slowdown of the Walker circulation driven by tropical Indo-Pacific warming. Nature, 491, 439-443, https://doi.org/ 10.1038/nature11576.

Vinogradova, N. T., and R. M. Ponte, 2013: Clarifying the link between surface salinity and freshwater fluxes on monthly to interannual time scales. J. Geophys. Res. Oceans, 118, 31903201, https://doi.org/10.1002/jgrc.20200.

$\longrightarrow$, and — 2017: In search of fingerprints of the recent intensification of the ocean water cycle. J. Climate, 30, 5513-5528, https://doi.org/10.1175/JCLI-D-16-0626.1.

Williams, P. D., E. Guilyardi, R. T. Sutton, J. M. Gregory, and G. Madec, 2006: On the climate response of the low-latitude Pacific Ocean to changes in the global freshwater cycle. Climate Dyn., 27, 593-611, https://doi.org/10.1007/s00382-006-0151-7.

,,,,--- , and,- 2007 : A new feedback on climate change from the hydrological cycle. Geophys. Res. Lett., 34, L08706, https://doi.org/10.1029/2007GL029275. 
G. Madec, S. Gualdi, and E. Scoccimarro, 2010: The role of mean ocean salinity in climate. Dyn. Atmos. Oceans, 49, 108-123, https://doi.org/10.1016/j.dynatmoce.2009.02.001.

Wu, Z. H., N. E. Huang, J. M. Wallace, B. V. Smoliak, and X. Y. Chen, 2011: On the time-varying trend in global-mean surface temperature. Climate Dyn., 37, 759-773, https://doi.org/10.1007/ s00382-011-1128-8.

Xie, S.-P., and Y. Kosaka, 2017: What caused the global surface warming hiatus of 1998-2013? Curr. Climate Change Rep., 3, 128-140, https://doi.org/10.1007/s40641-017-0063-0.

C. Deser, G. A. Vecchi, J. Ma, H. Y. Teng, and A. T. Wittenberg, 2010: Global warming pattern formation: Sea surface temperature and rainfall. J. Climate, 23, 966-986, https://doi.org/10.1175/2009JCLI3329.1.

Yu, L. S., 2011: A global relationship between the ocean water cycle and near-surface salinity. J. Geophys. Res., 116, C10025, https://doi.org/10.1029/2010JC006937.

, and R. A. Weller, 2007: Objectively analyzed air-sea heat fluxes for the global ice-free oceans (1981-2005). Bull. Amer. Meteor. Soc., 88, 527-540, https://doi.org/10.1175/BAMS-88-4-527.

, S. A. Josey, F. M. Bingham, and T. Lee, 2020: Intensification of the global water cycle and evidence from ocean salinity: A synthesis review. Ann. N. Y. Acad. Sci., 1472, 76-94, https:// doi.org/10.1111/nyas.14354. 